\title{
Association among genetic predisposition, gut microbiota, and host immune response in the etiopathogenesis of inflammatory bowel disease
}

\author{
P.J. Basso ${ }^{1}$, M.T.C. Fonseca ${ }^{1}$, G. Bonfá ${ }^{1}$, V.B.F. Alves ${ }^{2}$, H. Sales-Campos ${ }^{2}$ \\ V. Nardini ${ }^{2}$ and C.R.B. Cardoso ${ }^{2}$ \\ ${ }^{1}$ Departamento de Imunologia e Bioquímica, Faculdade de Medicina de Ribeirão Preto, \\ Universidade de São Paulo, Ribeirão Preto, SP, Brasil \\ ${ }^{2}$ Departamento de Análises Clínicas, Toxicológicas e Bromatológicas, Faculdade de Ciências Farmacêuticas de Ribeirão Preto, \\ Universidade de São Paulo, Ribeirão Preto, SP, Brasil
}

\begin{abstract}
Inflammatory bowel disease (IBD), which includes Crohn's disease (CD) and ulcerative colitis (UC), is a chronic disorder that affects thousands of people around the world. These diseases are characterized by exacerbated uncontrolled intestinal inflammation that leads to poor quality of life in affected patients. Although the exact cause of IBD still remains unknown, compelling evidence suggests that the interplay among immune deregulation, environmental factors, and genetic polymorphisms contributes to the multifactorial nature of the disease. Therefore, in this review we present classical and novel findings regarding IBD etiopathogenesis. Considering the genetic causes of the diseases, alterations in about 100 genes or allelic variants, most of them in components of the immune system, have been related to IBD susceptibility. Dysbiosis of the intestinal microbiota also plays a role in the initiation or perpetuation of gut inflammation, which develops under altered or impaired immune responses. In this context, unbalanced innate and especially adaptive immunity has been considered one of the major contributing factors to IBD development, with the involvement of the Th1, Th2, and Th17 effector population in addition to impaired regulatory responses in CD or UC. Finally, an understanding of the interplay among pathogenic triggers of IBD will improve knowledge about the immunological mechanisms of gut inflammation, thus providing novel tools for IBD control.
\end{abstract}

Key words: Inflammatory bowel disease; Crohn's disease; Ulcerative colitis; Immune response; Etiology; Microbiota

\section{Introduction}

Inflammatory bowel disease (IBD), which comprises Crohn's disease (CD) and ulcerative colitis (UC), is an uncontrolled inflammatory disorder of the gastrointestinal tract. These diseases affect mostly people between 30 and 40 years of age and, currently, the number of registered cases is increasing around the world (1). Since each country or continent establishes an appropriate methodology to collect their own data, it becomes difficult to accurately compare the distribution of IBD around the globe. Even so, most studies agree that Western countries, which include mainly North America and Western Europe, are the main contributors to the burden of IBD, although other regions also present a growing number of cases (1).
In Brazil, Victoria et al. (2) conducted a study in the midwest of São Paulo State, in which incidence rates were 4.48 and $3.5 / 100,000$, whereas the prevalence rates were 14.81 and $5.65 / 100,000$ for UC and CD, respectively. Thus, IBD requires constant monitoring of public health agencies, and more accurate studies are necessary in developing countries in order to determine the need for intervention, since the global burden is imminent.

The specific trigger for the onset of inflammatory responses in IBD is not completely established, but the interplay among immune deregulation, environmental factors, and genetic polymorphisms contributes to the complex and multifactorial nature of this pathology.

Correspondence: C.R.B. Cardoso, Departamento de Análises Clínicas, Toxicológicas e Bromatológicas, Faculdade de Ciências Farmacêuticas de Ribeirão Preto, Universidade de São Paulo, Av. do Café, s/n, 14040-903 Ribeirão Preto, SP, Brasil. Fax: +55-163602-4725. E-mail: cristina@fcfrp.usp.br 


\section{Genetic predisposition in IBD}

Regarding the genetic influence on $C D$ and UC, numerous polymorphisms have been identified and linked to the disease pathogenesis. Alterations in Toll-like receptors (TLRs) were related to IBD susceptibility (TLR4 and TLR9) and extensive colonic disease (TLR1, $T L R 2$, and $T L R 6$ ), while genetic variations in nucleotide binding oligomerization domain (NOD)-like receptors (NLRs) led to an increased predisposition to CD (3-5). Indeed, polymorphisms in NOD2/caspase recruitment domain-containing protein 15 (CARD15) were the first genetic modifications linked to IBD onset (5). Thereafter, genome-wide association studies have shown about 100 allelic variants related to different susceptibilities to CD or UC $(6,7)$. These include the NOD-like receptor family, pyrin domain containing 3 (NLRP3) inflammasome, autophagy-related 16-like 1 (ATG16L1), immunity-related GTPase family M protein (IRGM), and others, which are summarized in Table 1.

\section{Intestinal microbiota and IBD}

Along with genetic predisposition and environmental factors, microbiota is a key element in IBD pathogenesis, either as a mechanism that predisposes to or that protects against the development of intestinal inflammation. The direct relationship between altered microbiota and patients with CD or UC points to the microbial composition of communities resident in the gastrointestinal tract as one of the factors that could play a relevant role in the development and progression of IBD.

Accordingly, several studies have shown the role of specific and combined microorganisms in the severity of gut inflammation. For example, a reduction in anaerobic bacteria commonly found in intestinal microbiota such as Bacteroides (Bacteroidetes phylum), Eubacterium, and Lactobacillus species (Firmicutes phylum) has been reported in IBD patients (14). In CD patients, there are fewer Firmicutes bacteria and a simultaneous increase in Proteobacteria (15). These patients also present a reduction in the Clostridium leptum group, particularly Faecalibacterium prausnitzii (16).

Some of these reports about microbiota alterations in IBD are related to genetic factors, as observed in the risk alleles of NOD2 and ATG16L1 genes that have been linked to ileum CD (17). The disease phenotype in patients with these risk alleles is intimately associated with shifts in microbial composition. Moreover, the genetic changes were also associated with abnormalities in Paneth cell function (18), localized mainly in the ileum. These cells secrete antimicrobial peptides and thus function as potential controllers of lumen bacteria. Recently, variations in the FUT2 genotype were linked to substantial differences in the microbiota community composition and diversity (13). FUT2 is a gene responsible for the presence of $\mathrm{ABO}$ histo-blood group antigens in body fluids as well as in the gastrointestinal mucosa, and its deficiency is linked to susceptibility to infection and disease, including CD (13). All of these studies point to a substantial loss of bacterial diversity as a dominant factor in IBD pathogenesis. This reduction is characterized as dysbiosis, which may be responsible for a shift in the homeostatic healthy flora to detrimental proinflammatory microbial species, which can later predispose to intestinal inflammation $(19,20)$. The use of antibiotics also causes dysbiosis, providing further evidence for the role of microbiota in IBD pathogenesis. Indeed, the use of

Table 1. Examples of polymorphisms associated with inflammatory bowel diseases (IBD).

\begin{tabular}{lcc}
\hline Gene & $\begin{array}{c}\text { Putative changes in IBD } \\
\text { NOD2/CARD15 }\end{array}$ & Polymorphism associated to \\
NLRP3 & $\begin{array}{c}\text { Impairment of pathogen recognition and } \\
\alpha \text {-defensin secretion }\end{array}$ & Susceptibility to CD \\
ATG16L1 & Impairment of autophagosome formation & Susceptibility to CD and UC \\
IRGM & Impairment of the process of autophagy & Susceptibility to CD and UC \\
PTPN2 & Impairment of the process of autophagy in IEC & Susceptibility to CD and UC \\
FUT2 & Impairment of the secretion of ABO antigens & Susceptibility to CD \\
JAK-2/STAT3 & and alterations in gut microbiota & 10 \\
ICOSLG & Alteration in T cell activation? & 11,12 \\
CCR6 & Alteration in T cell activation? & Susceptibility to CD \\
& Alteration in leukocyte migration and activation & Susceptibility to CD \\
& at the inflammatory site? & Susceptibility to CD
\end{tabular}

ATG16L1: autophagy-related 16-like 1; CARD15: caspase recruitment domain-containing protein 15; CCR6: chemokine (CC motif) receptor type 6; CD: Crohn's disease; FUT2: fucosyltransferase 2; ICOSLG: inducible T-cell costimulator ligand; IEC: intestinal epithelial cells; IRGM: immunity-related GTPase family M protein; JAK-2: janus kinase-2; NLRP3: NOD-like receptor family, pyrin domain containing 3; NOD2: nucleotide-binding oligomerization domain 2; PTPN2: protein tyrosine phosphate non-receptor type 2; STAT3: signal transducer and activator of transcription 3; UC: ulcerative colitis. 
5-aminosalicylic acid or some antibiotics can suppress, but not eliminate, bacterial adherent biofilm in patients with IBD (21). However, some opportunistic bacteria like C. difficile can proliferate more than others during the use of antibiotics, causing disease that can range from mild diarrhea to colitis or toxic megacolon, and occasionally death, in patients who have received previous antimicrobial treatment (22).

Because commensal microbes produce numerous active metabolites, the microbiome is essential for several aspects of host health, such as metabolism, immune response, and physiology. Members of the Firmicutes phylum, which, as described earlier, are reduced in IBD (15), are known producers of short-chain fatty acid (SCFA) metabolites such as acetate and butyrate, which play an anti-inflammatory role in the gut (23). These are a preferred nutrient source for epithelial cells in the gastrointestinal tract, and their deficiency can induce a dysfunction, with subsequent disruption of the epithelial barrier. The commensal microbe-derived nutrient, butyrate, also plays an immune regulatory function, because it can drive the differentiation of regulatory $T$ (Treg) cells in vivo and in vitro by inducing the acetylation of histone $\mathrm{H} 3$ in the promoter of Foxp3 locus (23). As described in detail later, the balance between regulatory and effector responses is crucial to the outcome of inflammatory diseases like IBD, and Treg cells expressing the transcription factor Foxp3 are one of the main regulatory mechanisms required for disease control. In fact, by inducing Treg cells, butyrate can ameliorate colitis in mice, caused by adoptive transference of $\mathrm{CD}^{+}$ $\mathrm{CD}_{45 R B}{ }^{\text {hi }} \mathrm{T}$ cells into Rag1 ${ }^{-/-}$mice (23). Another bacterial intestinal product that potentiates Treg cell development in the periphery is propionate, a SCFA with epigenetic effects similar to butyrate, i.e., the inhibition of histone deacetylase (24).

Recently, a specific member of gastrointestinal microbiota was identified, the segmented filamentous bacteria (SFB), that is a critical inducer of Th17 cell proliferation in the intestine (25). It is known that this population of effector CD4 T helper lymphocytes is one of the major contributors to gut inflammation in IBD. In fact, mice expressing a human-derived antimicrobial peptide gene (DEFA5), showed a significant decrease in SFB, and, as a consequence, fewer interleukin (IL)-17-expressing T cells (26). Apart from the studies pointing to SFB in protection or inflammation, no definitive concern about their effect in IBD is totally clear. Indicative evidence for the role of this bacterial group during IBD is that mice deficient in aryl hydrocarbon receptor (AHR), known to develop a Th17 response, present a high prevalence of SFB, and, after administration of an antibiotic cocktail that targets these bacteria, the production of intestinal IL-17 is decreased (27). Altogether, these studies confirm the key importance of gut microbiota in the immunological balance that underlies the development of intestinal inflammation, and they point to future and on-going novel approaches for IBD treatment based on manipulation of the host microbiome.

\section{Immune aspects}

\section{Innate immune response in IBD}

Since IBD is a chronic and relapsing inflammation of the bowel mucosa, it is traditionally established that both innate and adaptive immune responses play an important role in the disease pathogenesis, together with the predisposing factors described earlier.

The innate immune system is the host's primary response against foreign aggressor agents. The customary innate response comprises physical barriers (e.g., the epithelium that covers the intestinal mucosa), phagocytic cells, dendritic cells (DCs), natural killer (NK) cells, cytokines, inflammation-related proteins (the complement system, C-reactive protein), antimicrobial peptides (defensins, cathelicidins), and pattern recognition receptors (PRRs). Most, if not all of these innate immune system components are modified in IBD, leading to an uncontrolled inflammation of the intestinal mucosa.

The epithelial barrier is a physical defense that comprises intestinal epithelial cells (IECs), tight junctions, and a layer of mucus (Figure 1). The IECs are responsible for absorption of nutrients or ions in the gut and for protection against penetration of resident microbiota, which can activate specific receptors, the PRRs, first in the epithelial cells (28). The subsequent downstream signaling in IECs leads to proinflammatory protein synthesis that engages in cross-talk with the immune system. Moreover, the epithelial barrier is more sensitive and permeable in patients with IBD (29), and IECs may be susceptible to an increased rate of apoptosis or shedding that contributes to the decrease in intestinal defenses (30).

Regarding tight junctions, the reduction of occludins and other related proteins, along with the decrease in structural complexity induced by proinflammatory cytokines [e.g., tumor necrosis factor (TNF)], also increase the permeability of the epithelium and subsequently impair its function (31). The proinflammatory cytokine IL-6 also influences IEC permeability by enhancing expression of claudin-2 (32). In addition, patients with UC and CD showed different patterns of mucin expression, which may be increased or decreased depending on the affected intestinal region, thus leading to defective mucus production (33). At first glance, therefore, most components of the epithelial barrier are altered in some way during IBD. Further studies need to be conducted in order to investigate whether a single trigger can lead to these changes or whether the sum of the changes acts together in the development of the disease.

Once these barrier alterations increase the gateway to pathogens in the intestine, IBD patients become more 


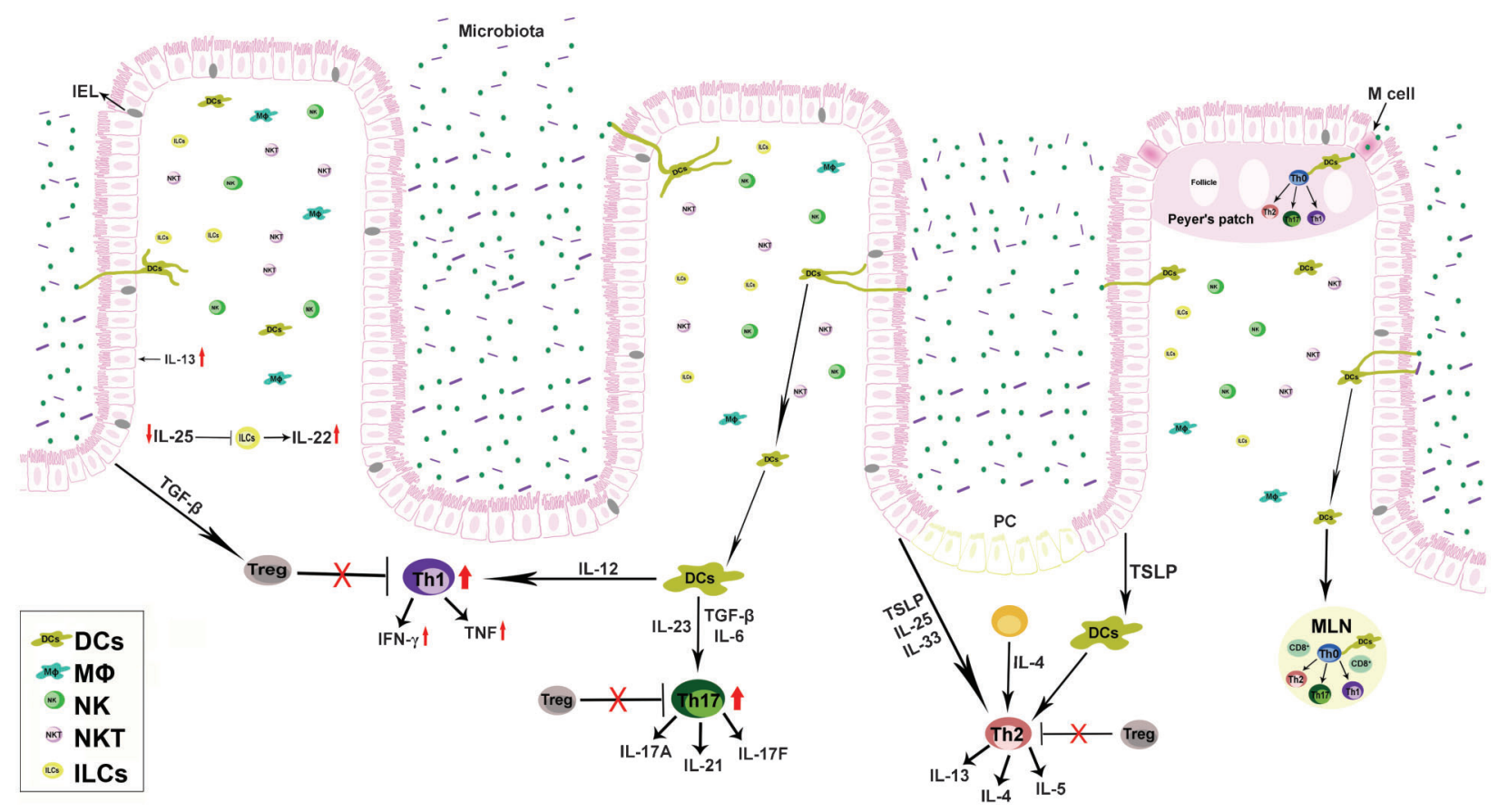

Figure 1. Intestinal immune response in the development of inflammatory bowel disease (IBD). The immune surveillance of the intestine is composed of several cell types, including dendritic cells (DCs), macrophages (MФ), natural killer (NK) cells, natural killer T (NKT) cells, innate lymphoid cells (ILCs) and intraepithelial lymphocytes (IEL). All these components are altered in some way during IBD. The breakdown of immunological tolerance causes recognition of the intestinal microbiota by the local immune system, activating the inflammatory cascade. The physical/chemical barriers composed by IEL, Paneth cells (PC), microfold cells (M cells) or their products are impaired during the disease and fail to restrain bacterial invasion. In lamina propria (LP), DCs capture and recognize bacterial antigens by projecting their dendrites into the intestinal lumen between intestinal epithelial cells (IEC), while in the Peyer's patches (PP) the antigens become available to DCs through M cells. Afterwards, the LP and PP DCs migrate to the mesenteric lymph nodes (MLN) and present the antigens to naive T cells (Th0). Meanwhile, the PP DCs may also present antigens to Th0 cells located in the follicles. The antigen presentation in the presence of the cytokines interleukin (IL)-12 or IL-23/IL-6/transforming growth factor-beta (TGF- $\beta$ ) leads to polarization of Th0 cells into a pro-inflammatory Th1 or Th17 profile, respectively, which are increased due to low number or function of regulatory T cells (Treg). Th1 and Th17 cells secrete cytokines such as tumor necrosis factor (TNF), interferon $\gamma$ $(\mathrm{IFN}-\gamma)$, IL17A, IL-17F and IL-21, which in turn contribute to tissue injury and excessive inflammatory response, especially in Crohn's disease. In addition, cytokines such as IL-4, IL-33, IL-25 and thymic stromal lymphopoietin (TSLP) directly or indirectly contribute to the differentiation of Th0 cells into Th2 profile in ulcerative colitis, which may also be under low control of Tregs. The red arrows indicate components that are altered in IBD. The red crosses indicate the absence or reduced function in IBD. It is noteworthy that cytokines and immune mechanisms depicted in the figure are shown according to the scope and information presented in this review. Thus, the mediators described here can also be synthesized from other cell sources as well as other immune pathways may contribute to IBD pathogenesis.

susceptible to bacteria translocation. Thus, antigens coming from the intestinal microbiota are available to gut resident cells [like antigen-presenting cells (APCs)] and constantly stimulate the immune system, which in turn enhances and extends local inflammatory activity (Figure 1). Then, because of the large amount of antigens supplied to APCs in the absence of intestinal homeostasis, the PRRs located in these cells, which may include IECS, are constantly activated, inducing the production of additional inflammatory mediators.

In the gut, excessive stimulation of TLRs located in different cell types like DCs, macrophages, neutrophils, NK cells, B cells, and others may lead to chronic inflammation. IBD patients have a different pattern of
TLR expression in IECs compared to healthy individuals, with increasing expression of TLR4 in UC and CD patients and decreasing expression of TLR3 in CD patients (34). Although presenting normal expression in IECs, TLR9 is unresponsive in IBD patients if challenged with cytidinephosphate-guanosine oligodeoxynucleotides (CpG), a specific ligand for TLR9 (35), and this finding seems to be very relevant, because signaling by this receptor may be important to disease control. In addition, overexpression of TLR4 and TLR2 in intestinal macrophages during inflammatory conditions contributes to the hyperresponsiveness of the immune system (36). These data corroborate studies that observed the improvement of disease using the TLR4-specific antagonist in murine 
models of IBD (37). Furthermore, polymorphisms in TLR1, TLR2, TLR4, TLR6, and TLR9 were identified in CD or UC. While TLR4 and TLR9 are associated with increased susceptibility to IBD development $(3,38)$, some of these changes (TLR1 and TLR2) seem to be related to the disease magnitude or to IBD-associated comorbidities such as pancolitis onset (4).

As stated earlier, cytoplasmic NLRs are intracellular PRRs expressed in many cell types, including IECs or APCs. These receptors recognize peptidoglycans from the bacterial wall, activating intracellular signaling pathways such as NF- $\kappa B$ (via kinase receptor-interacting protein 2) or inflammasome. Besides reducing the expression of $\alpha$-defensins and other antimicrobial peptides by Paneth cells, polymorphisms in NOD2 increase the susceptibility to luminal bacterial infection, while mutations in this molecule also interfere in autophagy and subsequent antigen presentation by DCs during IBD $(5,8,39)$. Furthermore, the decrease in both number and proliferation rate of intestinal epithelial lymphocytes is observed in $\mathrm{Nod}^{-/-}$mice as well as dysbiosis, which contributes to increased risk and poor outcome of disease in experimental models of colitis $(40,41)$. However, other studies showed augmented frequency of CD4 ${ }^{+}$Treg cells in the lamina propria of naive $\mathrm{Nod} 2^{--}$mice, thus partially explaining why polymorphisms in NOD2 (in humans) or the absence of this molecule in $\mathrm{Nod}^{-1-}$ mice are not sufficient, alone, to induce spontaneous intestinal inflammation (42).

DCs are essential to the control of immunity against pathogens and tolerance. They have a wide range of PRRs, including TLRs and NLRs, allowing them to distinguish between intestinal microbiota and pathogens. Thus, DCs may activate or silence $T$ cell responses (Figure 1). In healthy individuals, DCs exhibit an immature phenotype and induce nonresponsiveness of $\mathrm{T}$ cells. Typically, DCs reach the intestinal lumen by projecting their dendrites out of tight junctions between epithelial cells (43). With the large amount of antigens supplied to DCs in the inflamed intestinal epithelium, these leukocytes acquire a mature and activated phenotype, modifying the pattern of surface molecules (e.g., chemokine receptors, adhesion molecules) and thus inducing effective immune responses (44). There are also several subtypes of DCs that can be subdivided according to their different functions, location, or surface markers. Besides CD11b and CD11c, other integrins such as CD103 and $\mathrm{CX}_{3} \mathrm{C}$-chemokine receptor $1\left(\mathrm{CX}_{3} \mathrm{CR} 1\right)$ are also used in conjunction, to identify and to sort different DC subtypes (44). In the gut, there are CD103 ${ }^{+}$DCs that are essential for the steady state of the intestinal mucosa and that finely regulate the number of effector and Treg cells in this tissue (45). However, DC subsets expressing E-cadherin are present in the intestine during IBD and are related to the inflammatory profile found in the disease (46). The number of DCs and other APCs also appear to be increased in experimental colitis and in patients with IBD (44). Furthermore, DCs are more responsive to stimuli such as lipopolysaccharide in IBD and contribute to the exacerbation of the disease (47). In addition, monocytederived E-cadherin ${ }^{+}$DCs play an important role in experimental colitis by producing cytokines such as IL-6 and IL-23, which in turn contribute to T helper (Th) 17 cell development and colon damage (46). Apparently, TGF- $\beta 1$ may increase the inhibitory function of immature DCs in experimental colitis, probably by inducing CD4 ${ }^{+}$Foxp $3^{+}$ Treg cells (48).

Macrophages are another subset of APCs present in large quantities in body tissues, including the intestine (Figure 1). The function of these cells is to eliminate and present antigens to $\mathrm{T}$ lymphocytes, besides producing cytokines to recruit other immune cells to the inflammation site (28). Two major subtypes of macrophages have been described and they are commonly divided into inflammatory (M1) and anti-inflammatory (M2). In the gut, during intestinal homeostasis, the main population of macrophages displays a CX3CR $1^{\text {high }}$ phenotype and is nonresponsive to inflammatory stimuli, although their phagocytic capacity is preserved (49). However, in IBD, another subpopulation of macrophages, CX3CR $1^{\text {low/int }}$ expands due to the migration and differentiation of monocytes into the inflammatory site (49). This M1 macrophage overexpresses receptors [such as triggering receptor expressed on myeloid cells-1 (TREM-1) and PRRs] that amplify signaling for the synthesis of inflammatory cytokines (e.g., TNF, IL-1, and IL-6), which in turn exacerbates the local immune response (50).

The NK population can recognize injured cells and promote their death through absence of recognition for major histocompatibility complex class I. They may also produce cytokines, especially interferon gamma (IFN- $\gamma$ ), and influence the maturation of DCs. In IBD, NK cells have increased IL-21R expression, which results in greater action of IL-21 and proinflammatory cytokine production. This condition seems to polarize T helper cells to a Th17 profile (51). Recent studies have shown that there are two types of NK cells expressing the markers NKp44 or NKp46, and the ratio of these cells in the intestinal mucosa is altered in CD, thus contributing to disease progression (52).

Other leukocytes recently involved in IBD pathogenesis are the innate lymphoid cells (ILCs). They play a key role in tissue remodeling, combating microbes, lymphoid tissue development, and tissue homeostasis, including intestine $(53,54)$. Similar to their lymphoid progenitors, ILCs are divided into subtypes based on the pattern of cytokines synthesized and on the expression of specific transcription factors (53-55). It is known that these cells play an important role in gut homeostasis as well as in the pathogenesis of IBD (Figure 1). Cytokines synthesized by both ILCs and lymphocytes (IL-17, IFN- $\gamma$ ) may contribute to disease development or control. Studies have shown 
that IL-22-producing ILCs, which express AHR, are essential to restrain bacterial infection in the gut and are decreased in the intestine of AHR knockout mice, thus affecting mucosal immunity (55). Corroborating this finding, IL-22-producing ILCs are the main producers of IL-22 in the intestine, and this production is counterbalanced by IL-25 synthesis from IECs, which, in turn, is regulated by intestinal flora (Figure 1). Thus, when the intestinal barrier is disrupted, the fine interplay between commensal microbiota and the host is broken, with a subsequent increased IL-22 production (56). In addition, IL-22 protects the gut during inflammation in experimental colitis models (57). However, IL-23 causes colitis in mice by inducing ILCs to synthesize IL-17 and IFN- $\gamma$ and to promote the infiltration of these cells into the colon (54).

\section{Adaptive immune response in CD and UC}

Besides the important alterations in the innate immune response, the predominant cytokine profile in IBD will also depend on which $\mathrm{T}$ helper profile develops and thus the adaptive immune response that arises during the course of disease (Figure 1). Initially, around the 1990s, it was recognized that $C D$ and $U C$ differed from one another mainly because UC appeared to be mediated by Th2 cytokines, with elevated production of IL-5, while CD was mediated by a Th1 profile, characterized by increased IFN- $\gamma$ and IL-12 production, which activates the transcription factors STAT1 and STAT4, respectively (58). In fact, patients with $C D$ have increased production of IL-12 by lamina propria cells compared to controls (59), and, to better understand IBD pathogenesis, different animal models are used, most of them with immune responses driven against antigens of the normal mucosal microbiota with IL-12 and IFN- $\gamma$ production (60). In this context, the findings regarding participation of the Th1 response in IBD were reinforced by the fact that colitis induced by trinitrobenzene sulfonic acid (TNBS) or cell transfer in mice mimics $C D$ and generates an exacerbated Th1 inflammation, with high levels of IL-12, IFN- $\gamma$, and TNF $(57,60,61)$. In fact, colitis induced by TNBS is reversed by treatment with anti-IL-12p40 (60).

However, the concept that CD is mediated only by Th1 cells was recently reviewed after the description of the Th17 population that produces several proinflammatory cytokines such as IL-17A, IL-17F, IL-21, IL-22, and IL-26, which exert an important role in the development of IBD (62). Mice deficient in IL-17 or IL-21 have a milder colitis when compared to wild-type animals $(63,64)$. Moreover, in the absence of IL-21, naive $T$ cells from these knockout mice do not differentiate into Th17 cells (64). These data suggested that the immune response orchestrated by Th17 cells may amplify the inflammatory pathways during the development of intestinal inflammation (Figure 1). On the other hand, mice lacking IL-22 have severe colitis, with destruction of their gut architecture (57). The association of Th17 cells with IBD pathogenesis was also characterized in cell-transfer colitis models. RAG knockout mice that were deficient in IL-23p19 (subunit present in IL-23 and absent in IL-12) did not develop colitis when transferred with naive $\mathrm{T}$ cells and had a significant decrease in the production of TNF and IFN- $\gamma$. Yet, when $\mathrm{RAG}^{-/}$animals were deficient in IL-12p35 (subunit present in $\mathrm{IL}-12$ and absent in $\mathrm{IL}-23$ ) and received naive $\mathrm{T}$ cells, they developed colitis and had a moderate increase in TNF, IL-17, and IFN- $\gamma$ (65). Therefore, since IL-12 and IL-23 are essential for Th1 and Th17 differentiation, respectively, these results demonstrate the crucial involvement of Th17 cells in IBD pathogenesis. In addition, when SCID mice received antigen-specific $T$ cells from wild-type mice, five times more IL-17 compared to IFN- $\gamma$ was observed in the lamina propria of these animals (66), perhaps because these activated cells are more responsive to IL-23 than to IL-12.

Recently, it became clear that Th17 cells have certain plasticity and in an IBD context are not different, since these cells, when present in the inflamed gut of CD patients, can be characterized by $\mathrm{IL}-17^{+} \mathrm{IFN}-\gamma^{-}$, IL-

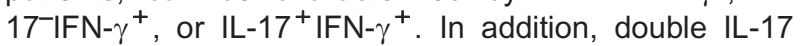
and IFN- $\gamma$ producing $\mathrm{T}$ cells have different features from Th1 cells; they are able to produce IL-22 and CCL20 and lead to the expression, in epithelial cells, of antimicrobial genes resembling Th17 cells (67). However, IL-17 ${ }^{+}$IFN$\gamma^{+}$cells are not stable, and under stimuli in vitro with IL-12 they may become IFN- $\gamma$ single-producing cells with proprieties of the Th1 lineage (67). It should be reemphasized that Th1 cells are also highly pathogenic in IBD, especially CD.

As stated earlier, cytokines involved in UC are from the Th2 pattern of immune response (Figure 1). The main model to study UC is through intrarectal administration of the hapten oxazolone, which causes a mild colitis associated with superficial inflammation in the gut, resembling human UC (68). In this model, there are cells producing IL-4 involved in Th2 conditions, and treatment of colitis with anti-IL4 prevents disease, whereas administration of anti-IL-12p40 exacerbates the intestinal inflammation or has no effect on the disease (68). In addition, in the oxazolone-induced experimental model of $\mathrm{UC}$, there is an initial production of IL-4 followed by a more prolonged response mediated by IL-13, which is responsible for the induction of the disease and is mainly produced by NK T cells (69). These observations prompted a search for CD1d-restricted NK T lymphocytes in the context of IBD and, surprisingly, a high frequency of type II NK T cells, which express a lot of different T cell receptors and cannot be identified because they do not respond to $\alpha$-galactosylceramide, was found in the inflamed tissue of a patient with colitis. Furthermore, these nonclassical NK T cells were responsible for the elevated amount of IL-13 in the gut of patients, besides being cytotoxic for intestinal epithelial cells $(70,71)$.

As mentioned previously, inflammation caused by 
proinflammatory cytokines produced by $\mathrm{CD} 4^{+}$effector $\mathrm{T}$ lymphocytes can be regulated by Treg lymphocytes. These cells are responsible for suppressing the uncontrolled immune responses against commensal microbiota or dietary antigens, thus being of great importance for gut homeostasis (72). Defects in Treg function or in their ability to contain effector cells are related to IBD pathogenesis (Figure 1).

The main findings regarding colitis protection by Treg cells emerged from cell transfer colitis models to mice with impaired immune systems. When immune-deficient mice receive $\mathrm{CD} 4^{+} \mathrm{CD} 45 \mathrm{RB}{ }^{\text {high }}$ naive $\mathrm{T}$ cells, colitis develops (73). The disease is counterbalanced by the transfer of $\mathrm{CD}^{+}{ }^{+} \mathrm{CD} 25^{+}$Treg cells, which protect against intestinal inflammation and result in the resolution of experimental IBD (73). In addition, the depletion of Treg cells in vivo, using an anti-CD25 antibody treatment, leads to worsening of intestinal inflammation in SAMP1/ YitFc (SAMP) mice. Furthermore, there is proliferation of $\mathrm{CD}^{-} 5^{-}$Foxp $3^{+}$cells, which do not have a regulatory function and presented inflammatory features (74). These observations provide evidence that the marker Foxp3 is not enough to indicate suppressor function of Treg cells.

The ability of regulatory $\mathrm{T}$ cells to control colitis is dependent on immunosuppressive cytokines such as TGF- $\beta$ and IL-10 $(75,76)$. Blockade of the TGF- $\beta$ signaling pathway in murine $T$ cells results in spontaneous colitis (77). In fact, some IBD patients present disorders in TGF$\beta$ signaling, caused by upregulation of the inhibitory molecule Smad7 (78), and in the lamina propria of these patients the Treg cell functions against effector $T$ cells can be restored by a Smad7 antisense oligonucleotide (78). On the other hand, mice deficient in IL-10 develop spontaneous colitis driven by microbiota (79), while children with mutations that result in loss of function of IL-10 receptor developed enteritis (80).

The main evidence that defects in Treg cells leads to the development of IBD in humans came from studies in patients with X-linked syndrome (IPEX). In this syndrome, a primary immunodeficiency disorder is caused by a mutation in Foxp3, and these individuals have significant intestinal inflammation (81). In addition, patients with IBD have decreased Treg cells in the peripheral blood compared to healthy controls (82), or these cells have less ability to suppress autologous T cell proliferation (83). There is evidence that Treg cells from peripheral blood and intestine of IBD patients are more susceptible to apoptosis than those from non-inflamed colon tissues, and in patients treated with anti-TNF there is a decrease in Treg cell apoptosis together with an increase in the number of these cells and reduction in disease activity (84). Once again, there is no complete evidence that Treg cells are functional or not, because these studies did not take into consideration all cell types capable of being suppressed by Treg cells. In addition, in vitro suppression assays usually do not contain all cytokines and immune mediators present in the original environment of the disease. Furthermore, it is noteworthy that several effector cells express Foxp3 and some Treg cells do not present this marker (85), so multiple studies could be reassessed to make sure that Foxp $3^{+}$cells have indeed a regulatory capacity that is lost during IBD.

Besides natural Foxp3 ${ }^{+}$Treg (nTreg) cells, which are derived from the thymus, there are many different types of regulatory lymphocytes that have been described, especially in the gut. Induced Treg (iTreg) cells are converted from naive $\mathrm{CD}^{+}{ }^{+} \mathrm{T}$ cells in the periphery, in the presence of TGF- $\beta$ (86). However, until now there have been no fully reliable markers that can distinguish iTreg cells from nTreg cells, and their mechanisms of action are very similar $(86,87)$. Beyond that, in the presence of IL-10 or after repeated antigen presentation, naive $\mathrm{CD} 4^{+} \mathrm{T}$ cells can be differentiated into IL-10-producing type 1 regulatory $\mathrm{T}$ cells $(\mathrm{Tr} 1)$. These CD4 ${ }^{+}$Foxp3 ${ }^{-} \mathrm{IL}-10^{+}$cells $(\operatorname{Tr} 1)$ are able to suppress both IL- $17^{+} \mathrm{IFN}-\gamma^{-}$and IL- $17^{+} \mathrm{IFN}-$ $\gamma^{+}$, producing $\mathrm{T}$ cells via cytokine-dependent mechanisms (mainly IL-10) in a colitis model (88). Moreover, it is known that the probiotic Bifidobacterium breve induced development of Tr1 cells that express IL-21, AHR, and cMaf in the gut, thus preventing intestinal inflammation (89). On the other hand, some bacteria like Bacteroides fragilis produce polysaccharide $A$ that can prevent experimental colitis by suppression of IL-17 production by intestinal immune cells, and this effect is related to IL10-producing $\mathrm{CD}^{+}{ }^{+}$Foxp $^{+} \mathrm{T}$ cells (90).

Altogether, although $\mathrm{T}$ cells are seen as key drivers of intestinal inflammation, there must be an association of knowledge between innate and adaptive immunity for a better understanding of the complex and differentiated intestinal mucosal immune system, especially during IBD.

\section{Concluding remarks}

Despite efforts employed to clarify the etiology and pathogenesis of IBD, the multifactorial aspects of the disease make this a difficult task. As far as we know, genetic factors and intestinal microbiota alterations lead to increased predisposition to CD or UC, with a large impact on the immune system. On the contrary, the vulnerability of some immune compartments and hyperactivity of others in susceptible patients may also facilitate gut dysbiosis and later contribute to damage observed in the disease. Hence, it is reasonable to speculate whether there is a single or predominant trigger in IBD development or whether these several alterations are required, together and simultaneously, to promote the disease. Furthermore, the sequence of these occurring events is also not yet totally clear and thus, to fill this gap, future studies are necessary in order to achieve a deeper and more complete understanding of IBD pathogenesis. 


\section{Acknowledgments}

The authors would like to thank FAPESP (\#2010/ 20162-7) and CNPq (\#482390/2013-1) for financial

\section{References}

1. Ng SC, Bernstein CN, Vatn MH, Lakatos PL, Loftus EV Jr, Tysk $C$, et al. Geographical variability and environmental risk factors in inflammatory bowel disease. Gut 2013; 62: 630-649, doi: 10.1136/gutjnl-2012-303661.

2. Victoria CR, Sassak LY, Nunes HR. Incidence and prevalence rates of inflammatory bowel diseases, in midwestern of São Paulo State, Brazil. Arq Gastroenterol 2009; 46: 20-25, doi: 10.1590/S0004-28032009000100009.

3. De Jager PL, Franchimont $D$, Waliszewska A, Bitton A, Cohen $A$, Langelier $D$, et al. The role of the Toll receptor pathway in susceptibility to inflammatory bowel diseases. Genes Immun 2007; 8: 387-397, doi: 10.1038/sj.gene. 6364398.

4. Pierik M, Joossens S, Van Steen K, Van Schuerbeek N, Vlietinck R, Rutgeerts $P$, et al. Toll-like receptor- 1 , -2 , and -6 polymorphisms influence disease extension in inflammatory bowel diseases. Inflamm Bowel Dis 2006; 12: 1-8, doi: 10.1097/01.MIB.0000195389.11645.ab.

5. Hugot JP, Chamaillard M, Zouali H, Lesage S, Cezard JP, Belaiche J, et al. Association of NOD2 leucine-rich repeat variants with susceptibility to Crohn's disease. Nature 2001; 411: 599-603, doi: 10.1038/35079107.

6. Anderson CA, Boucher G, Lees CW, Franke A, D'Amato M, Taylor KD, et al. Meta-analysis identifies 29 additional ulcerative colitis risk loci, increasing the number of confirmed associations to 47. Nat Genet 2011; 43: 246252, doi: $10.1038 / n g .764$.

7. Franke A, McGovern DP, Barrett JC, Wang K, RadfordSmith GL, Ahmad T, et al. Genome-wide meta-analysis increases to 71 the number of confirmed Crohn's disease susceptibility loci. Nat Genet 2010; 42: 1118-1125, doi: 10.1038/ng.717.

8. Wehkamp J, Harder J, Weichenthal M, Schwab M, Schaffeler E, Schlee M, et al. NOD2 (CARD15) mutations in Crohn's disease are associated with diminished mucosal alpha-defensin expression. Gut 2004; 53: 1658-1664, doi: 10.1136/gut.2003.032805.

9. Villani AC, Lemire M, Fortin G, Louis E, Silverberg MS, Collette $\mathrm{C}$, et al. Common variants in the NLRP3 region contribute to Crohn's disease susceptibility. Nat Genet 2009; 41: 71-76, doi: 10.1038/ng.285.

10. Palomino-Morales RJ, Oliver J, Gomez-Garcia M, LopezNevot MA, Rodrigo L, Nieto A, et al. Association of ATG16L1 and IRGM genes polymorphisms with inflammatory bowel disease: a meta-analysis approach. Genes Immun 2009; 10: 356-364, doi: 10.1038/gene.2009.25.

11. Barrett JC, Hansoul S, Nicolae DL, Cho JH, Duerr RH, Rioux JD, et al. Genome-wide association defines more than 30 distinct susceptibility loci for Crohn's disease. Nat Genet 2008; 40: 955-962, doi: 10.1038/ng.175.

12. Glas J, Wagner J, Seiderer J, Olszak T, Wetzke M, Beigel $F$, et al. PTPN2 gene variants are associated with susceptibility to both Crohn's disease and ulcerative colitis support. The research leading to these results also received support and funding from the Núcleo de Apoio à Pesquisa em Doenças Inflamatórias (NAPDIN) under grant agreement \#11.1.21625.01.0. supporting a common genetic disease background. PLOS One 2012; 7: e33682, doi: 10.1371/journal.pone.0033682.

13. Rausch P, Rehman A, Kunzel S, Hasler R, Ott SJ, Schreiber $\mathrm{S}$, et al. Colonic mucosa-associated microbiota is influenced by an interaction of Crohn disease and FUT2 (Secretor) genotype. Proc Natl Acad Sci U S A 2011; 108: 19030-19035, doi: 10.1073/pnas.1106408108.

14. Ott SJ, Musfeldt M, Wenderoth DF, Hampe J, Brant O, Folsch UR, et al. Reduction in diversity of the colonic mucosa associated bacterial microflora in patients with active inflammatory bowel disease. Gut 2004; 53: 685-693, doi: 10.1136/gut.2003.025403.

15. Walker AW, Sanderson JD, Churcher C, Parkes GC, Hudspith BN, Rayment $\mathrm{N}$, et al. High-throughput clone library analysis of the mucosa-associated microbiota reveals dysbiosis and differences between inflamed and non-inflamed regions of the intestine in inflammatory bowel disease. BMC Microbiol 2011; 11: 7, doi: 10.1186/14712180-11-7.

16. Willing B, Halfvarson J, Dicksved J, Rosenquist M, Jarnerot $G$, Engstrand L, et al. Twin studies reveal specific imbalances in the mucosa-associated microbiota of patients with ileal Crohn's disease. Inflamm Bowel Dis 2009; 15: 653-660, doi: 10.1002/ibd.20783.

17. Frank DN, Robertson CE, Hamm CM, Kpadeh Z, Zhang T, Chen $\mathrm{H}$, et al. Disease phenotype and genotype are associated with shifts in intestinal-associated microbiota in inflammatory bowel diseases. Inflamm Bowel Dis 2011; 17: 179-184, doi: 10.1002/ibd.21339.

18. Wehkamp J, Salzman NH, Porter E, Nuding S, Weichenthal $M$, Petras RE, et al. Reduced Paneth cell alpha-defensins in ileal Crohn's disease. Proc Natl Acad Sci U S A 2005; 102: 18129-18134, doi: 10.1073/pnas.0505256102.

19. Tamboli CP, Neut C, Desreumaux P, Colombel JF. Dysbiosis in inflammatory bowel disease. Gut 2004; 53: 1 4, doi: $10.1136 /$ gut.53.1.1.

20. Rooks MG, Veiga P, Wardwell-Scott LH, Tickle T, Segata N Michaud M, et al. Gut microbiome composition and function in experimental colitis during active disease and treatmentinduced remission. ISME J 2014

21. Swidsinski A, Weber J, Loening-Baucke V, Hale LP, Lochs $\mathrm{H}$. Spatial organization and composition of the mucosal flora in patients with inflammatory bowel disease. J Clin Microbiol 2005; 43: 3380-3389, doi: 10.1128/JCM.43.7.3380-3389. 2005.

22. Gerding DN. Clindamycin, cephalosporins, fluoroquinolones, and Clostridium difficile-associated diarrhea: this is an antimicrobial resistance problem. Clin Infect Dis 2004; 38: 646-648, doi: 10.1086/382084.

23. Furusawa $\mathrm{Y}$, Obata $\mathrm{Y}$, Fukuda S, Endo TA, Nakato G, Takahashi $D$, et al. Commensal microbe-derived butyrate induces the differentiation of colonic regulatory $\mathrm{T}$ cells. Nature 2013; 504: 446-450, doi: 10.1038/nature12721. 
24. Arpaia N, Campbell C, Fan X, Dikiy S, van der Veeken J, deRoos $\mathrm{P}$, et al. Metabolites produced by commensal bacteria promote peripheral regulatory T-cell generation. Nature 2013; 504: 451-455, doi: 10.1038/nature12726.

25. Ivanov II, Atarashi K, Manel N, Brodie EL, Shima T, Karaoz $\mathrm{U}$, et al. Induction of intestinal Th17 cells by segmented filamentous bacteria. Cell 2009; 139: 485-498, doi: 10.1016/ j.cell.2009.09.033.

26. Salzman $\mathrm{NH}$, Hung $\mathrm{K}$, Haribhai $\mathrm{D}$, Chu $\mathrm{H}$, Karlsson-Sjoberg $\mathrm{J}$, Amir E, et al. Enteric defensins are essential regulators of intestinal microbial ecology. Nat Immunol 2010; 11: 76-83, doi: $10.1038 /$ ni. 1825

27. Qiu J, Guo X, Chen ZM, He L, Sonnenberg GF, Artis D, et al. Group 3 innate lymphoid cells inhibit T-cell-mediated intestinal inflammation through aryl hydrocarbon receptor signaling and regulation of microflora. Immunity 2013; 39: 386-399, doi: 10.1016/j.immuni.2013.08.002.

28. Maloy KJ, Powrie F. Intestinal homeostasis and its breakdown in inflammatory bowel disease. Nature 2011; 474: 298-306, doi: 10.1038/nature10208.

29. Gerova VA, Stoynov SG, Katsarov DS, Svinarov DA. Increased intestinal permeability in inflammatory bowel diseases assessed by iohexol test. World $J$ Gastroenterol 2011; 17: 2211-2215, doi: 10.3748/wjg.v17.i17.

30. Kiesslich R, Duckworth CA, Moussata D, Gloeckner A, Lim LG, Goetz M, et al. Local barrier dysfunction identified by confocal laser endomicroscopy predicts relapse in inflammatory bowel disease. Gut 2012; 61: 1146-1153, doi: 10.1136/gutjnl-2011-300695.

31. Mankertz J, Tavalali S, Schmitz H, Mankertz A, Riecken EO, Fromm M, et al. Expression from the human occludin promoter is affected by tumor necrosis factor alpha and interferon gamma. J Cell Sci 2000; 113 (Part 11): 20852090.

32. Suzuki T, Yoshinaga N, Tanabe S. Interleukin-6 (IL-6) regulates claudin-2 expression and tight junction permeability in intestinal epithelium. J Biol Chem 2011; 286: 31263-31271, doi: 10.1074/jbc.M111.238147.

33. Buisine MP, Desreumaux $P$, Leteurtre $E$, Copin MC, Colombel JF, Porchet N, et al. Mucin gene expression in intestinal epithelial cells in Crohn's disease. Gut 2001; 49: 544-551, doi: 10.1136/gut.49.4.544.

34. Cario E, Podolsky DK. Differential alteration in intestinal epithelial cell expression of toll-like receptor 3 (TLR3) and TLR4 in inflammatory bowel disease. Infect Immun 2000; 68: 7010-7017, doi: 10.1128/IAI.68.12.7010-7017.2000.

35. Pedersen G, Andresen L, Matthiessen MW, Rask-Madsen $\mathrm{J}$, Brynskov J. Expression of Toll-like receptor 9 and response to bacterial $\mathrm{CpG}$ oligodeoxynucleotides in human intestinal epithelium. Clin Exp Immunol 2005; 141: 298-306, doi: 10.1111/j.1365-2249.2005.02848.x.

36. Hausmann M, Kiessling S, Mestermann S, Webb G, Spottl $\mathrm{T}$, Andus $\mathrm{T}$, et al. Toll-like receptors 2 and 4 are upregulated during intestinal inflammation. Gastroenterology 2002; 122: 1987-2000, doi: 10.1053/gast.2002.33662.

37. Fort MM, Mozaffarian A, Stover AG, Correia JS, Johnson DA, Crane RT, et al. A synthetic TLR4 antagonist has antiinflammatory effects in two murine models of inflammatory bowel disease. J Immunol 2005; 174: 6416-6423, doi: 10.4049/jimmunol.174.10.6416.

38. Torok HP, Glas J, Endres I, Tonenchi L, Teshome MY,
Wetzke $\mathrm{M}$, et al. Epistasis between Toll-like receptor-9 polymorphisms and variants in NOD2 and IL23R modulates susceptibility to Crohn's disease. Am J Gastroenterol 2009; 104: 1723-1733, doi: 10.1038/ajg.2009.184.

39. Cooney R, Baker J, Brain O, Danis B, Pichulik T, Allan P, et al. NOD2 stimulation induces autophagy in dendritic cells influencing bacterial handling and antigen presentation. Nat Med 2010; 16: 90-97, doi: 10.1038/nm.2069.

40. Jiang W, Wang $X$, Zeng B, Liu L, Tardivel A, Wei H, et al. Recognition of gut microbiota by NOD2 is essential for the homeostasis of intestinal intraepithelial lymphocytes. J Exp Med 2013; 210: 2465-2476, doi: 10.1084/jem.20122490.

41. Couturier-Maillard A, Secher T, Rehman A, Normand S, De AA, Haesler R, et al. NOD2-mediated dysbiosis predisposes mice to transmissible colitis and colorectal cancer. J Clin Invest 2013; 123: 700-711.

42. Amendola A, Butera A, Sanchez M, Strober W, Boirivant M. Nod2 deficiency is associated with an increased mucosal immunoregulatory response to commensal microorganisms. Mucosal Immunol 2014; 7: 391-404, doi: 10.1038/mi. 2013.58.

43. Niess JH, Brand S, Gu X, Landsman L, Jung S, McCormick BA, et al. CX3CR1-mediated dendritic cell access to the intestinal lumen and bacterial clearance. Science 2005; 307: 254-258, doi: 10.1126/science.1102901.

44. Varol C, Zigmond E, Jung S. Securing the immune tightrope: mononuclear phagocytes in the intestinal lamina propria. Nat Rev Immunol 2010; 10: 415-426, doi: 10.1038/ nri2778.

45. Annacker $\mathrm{O}$, Coombes JL, Malmstrom V, Uhlig HH, Bourne $T$, Johansson-Lindbom B, et al. Essential role for CD103 in the $\mathrm{T}$ cell-mediated regulation of experimental colitis. $J$ Exp Med 2005; 202: 1051-1061, doi: 10.1084/jem.20040662.

46. Siddiqui KR, Laffont S, Powrie F. E-cadherin marks a subset of inflammatory dendritic cells that promote $\mathrm{T}$ cell-mediated colitis. Immunity 2010; 32: 557-567, doi: 10.1016/j. immuni.2010.03.017.

47. Baumgart DC, Thomas S, Przesdzing I, Metzke D, Bielecki C, Lehmann SM, et al. Exaggerated inflammatory response of primary human myeloid dendritic cells to lipopolysaccharide in patients with inflammatory bowel disease. Clin Exp Immunol 2009; 157: 423-436, doi: 10.1111/j.1365-2249. 2009.03981.x.

48. Cai Z, Zhang W, Li M, Yue Y, Yang F, Yu L, et al. TGFbeta1 gene-modified, immature dendritic cells delay the development of inflammatory bowel disease by inducing CD4(+)Foxp3(+) regulatory $\mathrm{T}$ cells. Cell $\mathrm{Mol}$ Immunol 2010; 7: 35-43, doi: 10.1038/cmi.2009.107.

49. Bain CC, Scott CL, Uronen-Hansson H, Gudjonsson S, Jansson O, Grip O, et al. Resident and pro-inflammatory macrophages in the colon represent alternative contextdependent fates of the same Ly6Chi monocyte precursors. Mucosal Immunol 2013; 6: 498-510, doi: 10.1038/mi. 2012.89.

50. Schenk M, Bouchon A, Seibold F, Mueller C. TREM-1 expressing intestinal macrophages crucially amplify chronic inflammation in experimental colitis and inflammatory bowel diseases. J Clin Invest 2007; 117: 3097-3106, doi: 10.1172/ $\mathrm{JCl} 30602$.

51. Liu Z, Yang L, Cui Y, Wang X, Guo C, Huang Z, et al. II-21 enhances NK cell activation and cytolytic activity and 
induces Th17 cell differentiation in inflammatory bowel disease. Inflamm Bowel Dis 2009; 15: 1133-1144, doi: 10.1002/ibd.20923.

52. Takayama T, Kamada N, Chinen H, Okamoto S, Kitazume MT, Chang J, et al. Imbalance of NKp44(+)NKp46(-) and NKp44(-)NKp46(+) natural killer cells in the intestinal mucosa of patients with Crohn's disease. Gastroenterology 2010; 139: 882-92, 892, doi: 10.1053/j.gastro. 2010.05.040.

53. Cupedo T, Crellin NK, Papazian N, Rombouts EJ, Weijer K, Grogan JL, et al. Human fetal lymphoid tissue-inducer cells are interleukin 17-producing precursors to RORC + CD127 + natural killer-like cells. Nat Immunol 2009; 10: 66-74, doi: 10.1038/ni.1668

54. Buonocore S, Ahern PP, Uhlig HH, Ivanov II, Littman DR, Maloy KJ, et al. Innate lymphoid cells drive interleukin-23dependent innate intestinal pathology. Nature 2010; 464: 1371-1375, doi: 10.1038/nature08949.

55. Lee JS, Cella M, McDonald KG, Garlanda C, Kennedy GD, Nukaya M, et al. AHR drives the development of gut ILC22 cells and postnatal lymphoid tissues via pathways dependent on and independent of Notch. Nat Immunol 2012; 13: 144-151, doi: 10.1038/ni.2187.

56. Sawa S, Lochner M, Satoh-Takayama N, Dulauroy S, Berard $M$, Kleinschek $M$, et al. RORgammat+ innate lymphoid cells regulate intestinal homeostasis by integrating negative signals from the symbiotic microbiota. Nat Immunol 2011; 12: 320-326, doi: 10.1038/ni.2002.

57. Zenewicz LA, Yancopoulos GD, Valenzuela DM, Murphy AJ, Stevens S, Flavell RA. Innate and adaptive interleukin22 protects mice from inflammatory bowel disease. Immunity 2008; 29: 947-957, doi: 10.1016/j.immuni. 2008.11.003.

58. Fuss IJ, Neurath M, Boirivant M, Klein JS, de la Motte C, Strong SA, et al. Disparate CD4 + lamina propria (LP) lymphokine secretion profiles in inflammatory bowel disease. Crohn's disease LP cells manifest increased secretion of IFN-gamma, whereas ulcerative colitis LP cells manifest increased secretion of IL-5. J Immunol 1996; 157: 12611270.

59. Verdier J, Begue B, Cerf-Bensussan N, Ruemmele FM. Compartmentalized expression of Th1 and Th17 cytokines in pediatric inflammatory bowel diseases. Inflamm Bowel Dis 2012; 18: 1260-1266, doi: 10.1002/ibd.21905.

60. Neurath MF, Fuss I, Kelsall BL, Stuber E, Strober W. Antibodies to interleukin 12 abrogate established experimental colitis in mice. J Exp Med 1995; 182: 1281-1290, doi: 10.1084/jem.182.5.1281.

61. Oh SY, Cho KA, Kang JL, Kim KH, Woo SY. Comparison of experimental mouse models of inflammatory bowel disease. Int J Mol Med 2014; 33: 333-340.

62. Dige A, Stoy S, Rasmussen TK, Kelsen J, Hvas CL, Sandahl TD, et al. Increased levels of circulating Th17 cells in quiescent versus active Crohn's disease. J Crohns Colitis 2013; 7: 248-255, doi: 10.1016/j.crohns.2012.06.015.

63. Ito R, Kita M, Shin-Ya M, Kishida T, Urano A, Takada R, et al. Involvement of IL-17A in the pathogenesis of DSSinduced colitis in mice. Biochem Biophys Res Commun 2008; 377: 12-16, doi: 10.1016/j.bbrc.2008.09.019.

64. Fina D, Sarra M, Fantini MC, Rizzo A, Caruso R, Caprioli F, et al. Regulation of gut inflammation and th17 cell response by interleukin-21. Gastroenterology 2008; 134: 1038-1048, doi: 10.1053/j.gastro.2008.01.041.

65. Hue S, Ahern P, Buonocore S, Kullberg MC, Cua DJ, McKenzie BS, et al. Interleukin-23 drives innate and T cellmediated intestinal inflammation. J Exp Med 2006; 203 2473-2483, doi: 10.1084/jem.20061099.

66. Elson CO, Cong Y, Weaver CT, Schoeb TR, McClanahan TK, Fick RB, et al. Monoclonal anti-interleukin 23 reverses active colitis in a $\mathrm{T}$ cell-mediated model in mice. Gastroenterology 2007; 132: 2359-2370, doi: 10.1053/ j.gastro.2007.03.104.

67. Boniface $\mathrm{K}$, Blumenschein WM, Brovont-Porth $\mathrm{K}$, McGeachy MJ, Basham B, Desai B, et al. Human Th17 cells comprise heterogeneous subsets including IFNgamma-producing cells with distinct properties from the Th1 lineage. J Immunol 2010; 185: 679-687, doi: 10.4049/ jimmunol.1000366.

68. Boirivant M, Fuss IJ, Chu A, Strober W. Oxazolone colitis: A murine model of $\mathrm{T}$ helper cell type 2 colitis treatable with antibodies to interleukin 4. J Exp Med 1998; 188: 19291939, doi: 10.1084/jem.188.10.1929.

69. Heller F, Fuss IJ, Nieuwenhuis EE, Blumberg RS, Strober W. Oxazolone colitis, a Th2 colitis model resembling ulcerative colitis, is mediated by IL-13-producing NK-T cells. Immunity 2002; 17: 629-638, doi: 10.1016/S1074-7613(02) 00453-3.

70. Liao CM, Zimmer MI, Shanmuganad S, Yu HT, Cardell SL, Wang CR. dysregulation of CD1d-restricted type ii natural killer T cells leads to spontaneous development of colitis in mice. Gastroenterology 2012; 142: 326-334, doi: 10.1053/ j.gastro.2011.10.030

71. Fuss IJ, Heller F, Boirivant M, Leon F, Yoshida M, FichtnerFeigl S, et al. Nonclassical CD1d-restricted NK T cells that produce IL-13 characterize an atypical Th2 response in ulcerative colitis. J Clin Invest 2004; 113: 1490-1497, doi: $10.1172 / \mathrm{JCl} 19836$.

72. Cebula A, Seweryn M, Rempala GA, Pabla SS, Mclndoe RA, Denning TL, et al. Thymus-derived regulatory $T$ cells contribute to tolerance to commensal microbiota. Nature 2013; 497: 258-262, doi: 10.1038/nature12079.

73. Mottet $\mathrm{C}$, Uhlig HH, Powrie F. Cutting edge: cure of colitis by CD4 + CD25 + regulatory T cells. J Immunol 2003; 170: 3939-3943, doi: 10.4049/jimmunol.170.8.3939.

74. Ishikawa D, Okazawa A, Corridoni D, Jia LG, Wang XM, Guanzon M, et al. Tregs are dysfunctional in vivo in a spontaneous murine model of Crohn's disease. Mucosal Immunol 2013; 6: 267-275, doi: 10.1038/mi.2012.67.

75. Powrie F, Carlino J, Leach MW, Mauze S, Coffman RL. A critical role for transforming growth factor-beta but not interleukin 4 in the suppression of T helper type 1-mediated colitis by CD45RB(low) CD4 + T cells. J Exp Med 1996; 183: $2669-2674$, doi: $10.1084 /$ jem.183.6.2669.

76. Uhlig $\mathrm{HH}$, Coombes J, Mottet $\mathrm{C}$, Izcue A, Thompson $\mathrm{C}$, Fanger A, et al. Characterization of Foxp3 + CD4 + CD25 + and IL-10-secreting CD4 + CD25 + T cells during cure of colitis. J Immunol 2006; 177: 5852-5860, doi: 10.4049/ jimmunol.177.9.5852.

77. Gorelik L, Flavell RA. Abrogation of TGFbeta signaling in $T$ cells leads to spontaneous $T$ cell differentiation and autoimmune disease. Immunity 2000; 12: 171-181, doi: 10.1016/S1074-7613(00)80170-3. 
78. Fantini MC, Rizzo A, Fina D, Caruso R, Sarra M, Stolfi C et al. Smad7 controls resistance of colitogenic $T$ cells to regulatory T cell-mediated suppression. Gastroenterology 2009; 136: 1308-1316, doi: 10.1053/j.gastro.2008.12.053.

79. Kuhn R, Lohler J, Rennick D, Rajewsky K, Muller W. Interleukin-10-deficient mice develop chronic enterocolitis. Cell 1993; 75: 263-274, doi: 10.1016/0092-8674(93)80068P.

80. Glocker EO, Kotlarz D, Boztug K, Gertz EM, Schaffer AA, Noyan $\mathrm{F}$, et al. Inflammatory bowel disease and mutations affecting the interleukin-10 receptor. N Engl J Med 2009; 361: 2033-2045, doi: 10.1056/NEJMoa0907206.

81. Gambineri E, Perroni L, Passerini L, Bianchi L, Doglioni C, Meschi F, et al. Clinical and molecular profile of a new series of patients with immune dysregulation, polyendocrinopathy, enteropathy, X-linked syndrome: inconsistent correlation between forkhead box protein 3 expression and disease severity. J Allergy Clin Immunol 2008; 122: 1105-1112, doi: 10.1016/j.jaci.2008.09.027.

82. Eastaff-Leung N, Mabarrack N, Barbour A, Cummins A, Barry S. Foxp3 + regulatory T cells, Th17 effector cells, and cytokine environment in inflammatory bowel disease. J Clin Immunol 2010; 30: 80-89, doi: 10.1007/s10875-009-9345-1.

83. Ueno A, Jijon H, Chan R, Ford K, Hirota C, Kaplan GG, et al. Increased prevalence of circulating novel IL-17 secreting Foxp3 expressing CD4 + T cells and defective suppressive function of circulating Foxp3 + regulatory cells support plasticity between Th17 and regulatory T cells in inflammatory bowel disease patients. Inflamm Bowel Dis 2013; 19: 2522-2534, doi: 10.1097/MIB.0b013e3182a85709.
84. Veltkamp C, Anstaett M, Wahl K, Moller S, Gangl S, Bachmann $\mathrm{O}$, et al. Apoptosis of regulatory $\mathrm{T}$ lymphocytes is increased in chronic inflammatory bowel disease and reversed by anti-TNFalpha treatment. Gut 2011; 60: 13451353, doi: 10.1136/gut.2010.217117.

85. Wang J, loan-Facsinay A, van d, V, Huizinga TW, Toes RE. Transient expression of FOXP3 in human activated nonregulatory CD4 + T cells. Eur J Immunol 2007; 37: 129-138, doi: 10.1002/eji.200636435.

86. Horwitz DA, Zheng SG, Gray JD. Natural and TGF-betainduced Foxp3 $(+) \mathrm{CD} 4(+) \mathrm{CD} 25(+)$ regulatory $\mathrm{T}$ cells are not mirror images of each other. Trends Immunol 2008; 29: 429-435, doi: 10.1016/j.it.2008.06.005.

87. Shevach EM. Mechanisms of foxp3 $+\mathrm{T}$ regulatory cellmediated suppression. Immunity 2009; 30: 636-645, doi: 10.1016/j.immuni.2009.04.010.

88. Huber S, Gagliani N, Esplugues E, O'Connor W Jr, Huber FJ, Chaudhry A, et al. Th17 cells express interleukin-10 receptor and are controlled by Foxp3(-) and Foxp3+ regulatory $\mathrm{CD} 4+\mathrm{T}$ cells in an interleukin-10-dependent manner. Immunity 2011; 34: 554-565, doi: 10.1016/ j.immuni.2011.01.020.

89. Jeon SG, Kayama H, Ueda $\mathrm{Y}$, Takahashi $\mathrm{T}$, Asahara $\mathrm{T}$, Tsuji $\mathrm{H}$, et al. Probiotic Bifidobacterium breve induces IL-10producing Tr1 cells in the colon. PLoS Pathog 2012; 8 : e1002714, doi: 10.1371/journal.ppat.1002714.

90. Round JL, Mazmanian SK. Inducible Foxp3 + regulatory Tcell development by a commensal bacterium of the intestinal microbiota. Proc Natl Acad Sci U S A 2010; 107 : 12204-12209, doi: 10.1073/pnas.0909122107. 